\title{
How does Incentive Affect Kidney Donation Rates: Turkey Case
}

\author{
Yavuz Demirdogen \\ Yildirim Beyazit University
}

\begin{abstract}
Renal disease is an ongoing and growing problem around the world and in Turkey. Almost $\% 5$ of health expenditures are about kidney patients in Turkey. The amount of patients is increasing every day although the donation rates are not increasing in the same speed. The governments are applying different regimes for closing the gap between supply and demand on kidney. These systems are not accurate to close this gap. Main classification of these techniques is opt - in and opt - out regimes. The cost of dialysis for every patient is higher than the cost of transplantation. The transplanted patient lives 22 years whether dialysis patient lives 14 years. Transplantation is cost -effective than dialysis. It is an obligation to decrease the number of patients in the waiting list. In 2014 there are almost 60.000 kidney disease patients in Turkey and 29.000 of them are ESRD patients. Almost 4200 of them are transplanted in 2014. One of the solutions of closing this difference is to pay monetary incentive to possible living donors. Among the ethical debates on monetarizing the human body, this article is focused on the quantity of monetary incentive that would pay to the possible donors. This amount is the collection of the costs of statistical value of life, death-risk component, quality of life component and value of time. It is the quantity of losses, not the value of a kidney. The quantity differs according to the value of statistical life. Average price for these losses are 8.638 TL.
\end{abstract}

Keywords: ESRD, Monetary incentive, Kidney disease, Kidney transplantation.

JEL Codes: I110, I150, I180

\section{INTRODUCTION}

Renal impairment is a disease which is rapidly approaching to be a problem in Turkey and in the world. From the first kidneytransplantation surgery till today, supply of kidney is still standing as an unsolved problem. Although this problem is tried to be overcome by peritoneal dialysis and hemodialysis techniques, the diseaseis not healing; but only being delayed. Since producing a kidney in laboratory conditions or refunctioning an ineffective kidney is impossible, the last solution, which renal impairment patients refer to at the last phase of their disease, is kidney transplantation. There is no cure for End Stage Renal Disease (ESRD) patients other than transplantation. 
Curing the disease with the transplantation of a kidney is more effective than holding on the life with dialysis. While the average life year of transplanted patient is 21,6 years, the average life year of dialysis patient is 13,8 years (Harihan et al.:2000). When considered from the costs point of view, the cost of transplantation, even with a rough calculation, is less than the costs of dialysis. ${ }^{1}$ If all unrelated costs like transportation, lodging, labor-loss are added to this calculation, one can see the advantage of transplantation.

At this stage, kidney supply problem for transplantation is arising. Different methods are used and tried to overcome this supply problem. The method used in many countries is "Altruistic Donation". Whether this system differs in content and practice, international data shows that it is unsuccessful (Irodat 2013). Waiting list is growing day by day, buton the other hand donation quantities are stand nearlyat the same level. At this point, academicians express that different and effective methods must be implemented.

Main axis of method change proposal constitutesmonetary incentive. Matas, who wrote several essays on the subject, published the results of the study group constituted in 2012 for the research about the incentives and legal regulations. (Matas: 2012).

Applying monetary incentive fororgan donation (it can be named as selling kidney) is a subject that has different aspects. One of these aspects is about the fact that organ donation should definitely be on voluntary basis. In America and England, government applied payment on blood donation for a period and a decline at donation rate was observed. Based on this example, some academicians defend the opinion that if monetary incentive is allowed, donation rates will decline. Conducted surveys have showed that people rather prefer donating their organs instead of selling them (Mohamer \& Guella: 2013; Mayrhofer-Reinhartshuber: 2006; Evans: 2003; Leider \& Roth: 2010; Bilgel: 2011). But results of these surveys are closely related with the questions and demographic structure of the participants. These surveys have generally been applied in or around the university. It is expected that people who are willing to sell his kidney would be poorer and having financial difficulties. It is possible to have different results if these surveys are applied at places in which low-income group of people live.

Selling kidney has several dimensions. First of all, from whom will the kidney be taken, from a living person or from a cadaver? While if it is a cadaver, not only kidneys but also eye, tissue, heart, lung, liver and other organs could be taken; if it is a living person, only kidney and part of the liver could be transplanted. For this reason,

\footnotetext{
${ }^{1}$ Government pays $158 \mathrm{TL}$ for each dialysis session. Almost $\% 96$ of the patients is having dialysis 3 times a week. Cost of dialysis for a patient in a year is: $158 \times 3 \times 52$ $=24648$ TL. Payment for transplantation is $35000 \mathrm{TL}$ on average. All the costs are paid by government health expenditures.
} 
at the center of most researches there is kidney transplantation.

Monetary incentive also has several dimensions. Indirect incentive is one of these methods. The reason why it is "indirect" is that it is not paid directly in cash. The proposals about indirect incentives are concentrated into three groups: tax impulsion; insurance and health expenditure incentives; and reimbursement of expenses. Incentive mechanisms proposing covering health expenses besides tax support are also among proposals (Peters: 1991). Even these kind of incentives have been proposed, they haven't been applied in America (Pennsylvania and Wisconsin) (Ubel et al.:2000). Again in Pennsylvania, although net payment for funeral and hospital expanses is proposed, they have not been applied (Ubel et al.:2000).

Another system proposes direct incentive. Direct incentive is based on making payment in cash to donor or donor's family. In this type of system, different alternatives are proposed about the quantity and the way of the payment. Quantity of the payment has become a different subject for discussions. One of the simple ways to identify the quantity is to take the price of kidney in the black market. But the price at the black market differs with respect to middle-men, donor, and recipient and also from country to country. For this reason, considering the price of the black market will not be the correct choice.

Another proposal for the quantity of the payment is the difference between dialysis and transplantation costs. Difference between the cost of dialysis for one year (or afew years) and transplantation costs will directly be paid to the donor (Matas: 2012).

The most solid calculation is the one mentioned in Becker and Elias's article handling monetary incentive in 2007 (Becker \& Elias: 2007).

At this paper, the author makes the calculation based on the donor's labor-loss, hospital expenditures, lounge, food and beverage costs, monetary equivalence of the impaired quality of life, monetary equivalence of the risk of death during or after the surgery and the statistical value of life basis. In this study, Becker and Elias's calculations will be adapted to our day and to Turkey.

Another system is paying a net payment that the government determined. This system is already active in the only country that allows the trade of kidney; Iran. In this model that is called the Iranian model, the government or an entity that is authorized by government make a sum of payment; if the donor demands an additional payment, it will be paid by the recipient. If the recipient cannot afford this payment, the remaining amount would be paid by a charitable foundation (Ghods \& Savaj: 2006).

Some studies have been conducted about the amount of money 
that people would be willing to sell their kidney. These studies are generally concentrated on determination of this amount by surveys. Hoeyer et al categorized the papers of financial support models on social behaviors and summarized their results (Hoeyer et al.:2013). According to this analysis, American people are more consentient to sell organs with respect to European people. The study that is among the rest surveys is the study conducted by Adams, Barnett and Kasermann in 1999. According to this survey, a 117\% increase is foreseen on donation rates with $\$ 1000$ incentive. If incentive quantities are more than $\$ 1000$, it would result a little bit more increase but this increase is not radical (Adams et al.:1997). The subjects handled at some of the surveys focused on the question: "if there is financial incentive, will you donate?" rather than the quantity (Mohamed \& Guella: 2013; Mayrhofer - Reinhartshuber: 2006).

Another debate is from whom the organ will be taken. Some of the authors defend that the donor must only be cadavers (Robertson: 1999). But researches showed that; even if organs are taken from the entire eligible cadavers, the demand would not be met (Sheey et al.:2003).

Other than these, some other methods to increase the organ donation come to the fore. The other proposal than can be considered in the incentive scope is the small scaled "encouraging" incentives. The primary one of these is making discounts at driving license fees in exchange for tagging as donor in driving licenses. This application does not directly target to increase donation, but aims to increase the donor numbers. This system is actually in practice at Georgia with $\$ 7$ discount-incentive per person. According to researchers' results, this type of incentive results in a comparable growth at donor numbers (Jasper et al.:1999; DeJong et al.:1995).

\section{KIDNEY TRANSPLANTATION AND DIALYSIS IN TURKEY}

From the first kidney transplantation in 1975 (Karaali\& Haberal:2005) till today, kidney transplantation in Turkey showed a serious increase in quality and quantity. With the help of the legal regulations, that renewed and updated in time, the quality, speed and security of the transplantation has increased. But, since the opt-in regime is still applied in Turkey, the kidney demand is irretrievable. Every day the number of dialysis patients is increasing everyday but kidney supply is not increasing adequately. Although Turkey takes place on the top on living donor numbers $(46,6 \mathrm{pmp})$, it is pretty far behind being the leading country at cadaver donations $(5 \mathrm{pmp})$ and take part at the middle parts of world ranking in the mean (IRODAT 2014). The health expenditures on dialysis and transplantation, 
exceeds $2 \%$ of the health ministry ${ }^{2}$ (www.saglik.gov.tr). When it is considered that transplantation is more profitable than dialysis for the government, being donor should be encouraged.

Ministry of Health data from 2014 appearing at the web site (www.organ.saglik.gov.tr) will be used in the following parts of the study. According to these data, number of transplantation in 2014 is 4263 and patients in the waiting list are 25337 . There is only one donor death occurred after transplantation. All of the dialysis and transplantation expenses either for donor or for recipient are paid by Social Insurance System. 59\% of dialysis patients are registered to the Social Insurance System.

The data are beginning from the year 2011 at the official website. There are no radical changes in dialysis patients, number of donor and number of transplantationsin the given years. In this content, using 2014 datafor the proceeding calculations is considered suitable.

\section{ECONOMIC ANALYSIS OF MONETARY INCENTIVE}

Among the proposals for increasing the transplantation quantity, monetary incentiveis being written widely in academic literature in recent years. Becker and Elias are the pioneers about the rational determination of the amount that would be paid (Becker \& Elias: 2007). In their calculation for the monetary incentive, they took three main matters as principals: the first one is monetary incentive for death risk, the second one is monetary incentive for the healing period and third one is monetary incentive with respect to decreasing life quality.

First of all, the price of the death risk is calculated. Life-loss during the transplant surgery is about $1 \%$ in USA. This ratio is about $0,0235 \%$ in Turkey (see Appendix). For the calculation of the optimal value, Statistical Value of Life (SVL) is needed. There is no such calculated SVL for Turkey currently. According to World Health Organization (WHO), there exist a calculated SVL for Eurozone which is 2.487.283 Euro $^{3}$ and this quantity will be converted to Turkish Lira (TL) and used in this article. The SVL, which is necessary for these kind of calculations, must be calculated by Ministry of Health or Turkish Statistical Institute (TSI). However, it is not calculated because of different reasons except for developed countries. In the sensitivity analysis, the most suitable value for the statistical value of life in various amounts will be calculated.

The monetary equivalent found depending on the statistical

\footnotetext{
${ }^{2}$ Dialysis expenditure per patient multiplied by number of dialysis patients and average expenditure of transplantations are added according to health ministry data. 2014 health ministry budget is used.

3 http://www.heatwalkingcycling.org/index.php?pg=requirements\&act=vsl\&PH PSESSID=q3jkco40bnm8aj7poon2v765o5
} 
value of human life of the probability of dying during the surgery is approximately 906,41 TL. The calculation can be seen at Appendix (1).

As the second component is the value of monetary-loss during the treatment process. The determination is done by calculating the healing period as approximately 4 weeks. Although this period is not fully healing period, it is enough duration to return working in full capacity again. The rest of the period is foreseen as medical treatment. For calculating the money-loss during recovery, the lowest civil servant salary is used and semi-annually salary raise is ignored. Within these constraints, the value of recovery period is approximately 1.951,4 TL (see Appendix).

As the third component, the calculation of the value of change in life quality should be calculated. While doing this calculation, SVL must be multiplied with Quality Adjusted Life Years (QALY). Since there is no calculated QALY value for Turkey, the quantity of Becker and Elias' article is used. In the light of this information, the quantity is approximately calculated as 5779.8 TL (see Appendix). The calculated values are primarily in direct relationship with SVL (Viscusi \& Aldy: 2003). Generally, it is calculated for health sector so the amount that is calculated by WHO is used. According to these results, optimum monetary incentive for grafting a donor's kidney is approximately 8.638 TL.

The cost of transplantation is also needed for proper evaluation. For that reason, 55.000 TL that is the standard payment of the government for transplantation is taken. So, demand percentage change is found as $21,85 \%$. When the demand function has unit elasticity, it will make $21,85 \%$ effect on transplantation demand.

To calculate the effect of this percentage change on the transplantation amount, total kidney demand in 2014 will be used. While the total demand for kidney was 29600 in 2014, the number of transplantation was 4263. Number of patients in the waiting list was 25337 (www. Donor.saglik.gov.tr). In this case, the effect of change on demand will be 6466 . So, the amount requested after the change will decrease to 27397. The necessary amount will decrease as 16668 since the demand will lessen in the case of monetary payment is done for the kidney. With a $21,85 \%$ decrease in the demand, whole requested amount of kidney will be met. In this case, the transplantation number will increase to 27397 . So the percentage increase in demand of kidney after payment to donors will be $485,3 \%$. Theoretically, these increases will be enough to cover all kidney demand.

\subsection{Sensitivity Analysis}

As indicated at previous sections, the effect of monetary incentive on organ transplantation depends on two factors: the first is the effect of payment for organ to transplantation costs;and 
the second is the demand elasticity of organ transplantation (Becker \& Elias: 2007). In this section, the change of demand and transplantation amount with respect to price changes will be analyzed.

Since the statistical value of life appearing in the first column differs according to calculation techniques and sectors, SVL will be used as a variable in the sensitivity analysis. In the second column, risk of death component is held constant. Since it does not differ with respect to person or system, this ratio is taken as $0,0235 \%$. Change in SVL will affect this result.

In the third column, since QALY component is also the same, 0,0014985 is taken as a multiplier. Since this column will also differ according to SVL; changes in this column are the result of the changes in SVL. The monetary equivalence of labor-loss can be seen in the fourth column. The minimum civil servant salary is taken basis for calculation so no change is expected in this column. For this reason the number is held stable.

After all the components are added,it is seen that the price of the kidney ranges between 5300 TL to 12000 TL. Price elasticity of demand is taken as -1 for kidney transplantation which is corresponding to $527 \%$ to $443 \%$ change on transplantation amounts. Even the SVL is calculated higher, the change in total transplantation amount stands out as high.

At this stage, the importance of the components rises to the surface. First of all, since the life of human is in question, statistical value of the life must be known for the calculations. The other one, death risk component, shows the monetary incentive given to donor in return for having risk of death during or after the surgery. For calculating this component, the SVL must be known, too. Donor will have a "life-quality" loss because of an organ deficiency. Although this loss will not be so high to affect the rest of his life substantially, a loss is in question to a certain extent. While this lifequality loss ratio is not explicitly given in Becker and Elias's article, it is taken from the calculations. Since this ratio is independent from country or values, it is constant. Lastly, since the donor loses "time" for healing, the monetary value of the lost time period must be calculated.

\section{Inquiry 2016/1}

Table 1: Sensitivity Analysis

\begin{tabular}{|l|l|l|l|l|l|l|}
\hline $\begin{array}{l}\text { Statistical } \\
\text { Value of Life }\end{array}$ & $\begin{array}{l}\text { Death-risk } \\
\text { component }\end{array}$ & $\begin{array}{l}\text { Quality of life } \\
\text { component }\end{array}$ & $\begin{array}{l}\text { Value of } \\
\text { time }\end{array}$ & $\begin{array}{l}\text { Total } \\
\text { kidney } \\
\text { value }\end{array}$ & $\begin{array}{l}\% \text { change } \\
\text { in price }\end{array}$ & $\begin{array}{l}\% \text { change in } \\
\text { total trans- } \\
\text { plantation } \\
\text { amount }\end{array}$ \\
\hline 1928541 & 453,2 & 2890 & 1951,4 & 5295 & 9,63 & 527,51 \\
\hline 3101440 & 728,8 & 4648 & 1951,4 & 7328 & 13,32 & 501,84 \\
\hline 3857080 & 906,4 & 5780 & 1951,4 & 8638 & 15,70 & 485,30 \\
\hline
\end{tabular}




\begin{tabular}{|l|l|l|l|l|l|l|}
\hline 4652161 & 1093,3 & 6971 & 1951,4 & 10016 & 18,21 & 467,90 \\
\hline 5785621 & 1359,6 & 8670 & 1951,4 & 11981 & 21,78 & 443,10 \\
\hline
\end{tabular}

When it is considered that the costs of dialysis - even if the highest SVL is taken for calculation - are more expensive than total kidney value, it can be said that giving monetary incentive payment will result in decreasing/ending kidney waiting-list patients and also gainin economy will be higher.

The graphic below shows the relationship between percentage change in price and percentage change in transplantation with respect to the percentage change in price. As it can be understood from the graphic, while percentage changes are not redundant and rapid, fast decreases in percentage changes of transplantation are observed. As the reason of that, the gap between transplantation needs and transplantation amounts can be suggested. Since there are great differences between actual kidney transplant numbers and kidney requirements, a small percentage change will cause dramatic changes on transplantation amounts. Even in the case that the price increases; kidney amount and transplant amount that would be demanded (under the assumption that all the demand is met) are still very high. The numbers in this article shows the minimum monetary incentive to be paid in the case the market is set free. Since the prices billed to the receiver in the black market are highly higher than this amount, even the price increases, there will still be (a lot of) buyers.

Graph 1: Percentage Change in Total Transplantation

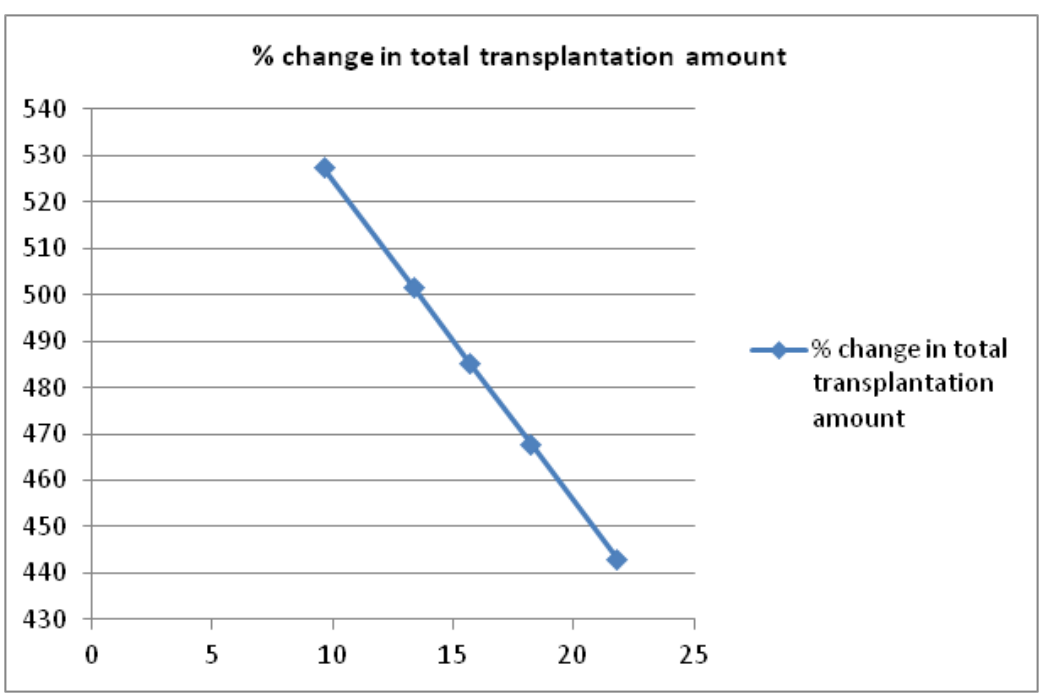




\section{THE BENEFITS OF DECREASING THE WAITING LIST}

According to Ministry of Health data, waiting time in the kidney waiting-list is approximately 7 years. It is not certain to find a kidney in this period. Since the majority of the kidney patients are above 60 years, survival of these patients in this waiting period is doubtful. Nonetheless, diabetics and cardiac failure arises together with the kidney failure (Stel et al.: 2012). When the necessity of providing physiological support to the patients is considered, the cost of renal failure disease is further increasing. Besides, these expenditures are not enough to heal the disease.

Decrease in waiting time means that the patients would get healthy again sooner than anticipated. A dialysis patient cannot be fully productive during his/her life and besides always require support and medical care. When considered from this perspective, every dialysis patient is restraining another person to participate in production/labor force.

In general, kidney patients are trying to cover the dialysis and treatment expenses by him at the beginning. This results in a wealth loss to some extent.

Extension of waiting time is also a factor affecting the patient's recovery during and after the transplantation. If the recipient suffers from ESRD for a long time, he/she becomes unavailable for transplantation. Death is a matter of time for these kinds ofpatients. The extension of waiting time causes a major decrease of the patients' life quality and causes a significant deterioration.As long as the time passes, the patients as well as his/her beloveds become nervous. So, social welfare loss for this type of patients and their next-of-kin is inevitable.

The difference between supply and demand of kidney is growing day by day. This difference results in extension of waiting time. This extension leads patients to try illegal ways to find kidney. Since this problem cannot be eliminated in a short time, patients have to find different, illegal and unethical ways. The government does not have solid and quick solutions for ESRD patients. This gap will be fulfilled by kidney black market. It is obvious that, donation system cannot meet the demand. Donation encouraging systems, mechanisms and advertisement policies are not satisfying the needs. On the other hand, ESRD patients are dying day by day and these patients do not have time to wait for a "legal" kidney. Since there is not any governmental control on the market, middlemen have exorbitant gains. Not applying an effective enforcement to the caught buyers, sellers and middlemen can be seen as one of the reasons of not being able to prevent black-marketing. Illegal organizations prefer the countries that have legal loopholes. Turkey was one of the haunted until the re-regulations on the legislation in 2012. Transplantation centers and the competence of 
transplantation teams are advanced in Turkey. Turkey is competing with U.S., in which the first transplantation occurred and who is applying transplantation in an advanced way.

Illegal transactions are continuing on one side, on the other side people are dying because of the length of the waiting list. The main problem here is because of legal regulations. When the regulations are directed to eliminate the difficulties like Iran, illegal market will vanish, patients will gain their health as well as the money-loss will turn to economy.

Within the donation system, patient would have his health (gain), surgical team and hospital would have its fee (gain) but donor and his family would not get any winnings (loss). The unique gain for donor is the moral satisfaction from saving another's life. This motivation is not enough most of the time. Although Turkey is ranked as the first on living donation rates around the world, it is on average about deceased kidney donation rates per million capita. By current donation mechanisms, it seems impossible to close this gap. At this stage, it is a must that the authorities change their perspective.

There are some problems about being adonor from the individuals' perspective. People think that if they will be signed as a donor, their organs will betaken before death or their medical records could be sold to middlemen and they could be "hunted" by them. It must be explained properly and explicitly to the people that these records are private and unattainable by othersand their organs cannot be taken before death. On the other hand, for eliminating the religious reasons, there must be a proper and effective integration between Religious Affairs and government.

The studies conducted to increase donation rates finds responses immediately. Encouraging applications done by Ministry of Health in recent years raised the donation rates to some extent. Thanks to campaigns, donation rates had increased by $259 \%$ between 2007 and 2014. After the legal regulations for increasing donation that was supported by effective and comprehensive advertisement campaigns

Inquiry 2016/1 between 2010 and 2014, donation growth rate was almost \% 140 (by the end of 2013, 51,6 ppm). Even though these results may seem promising, the vast majority of donations are from living donors and generally close relatives (by the end of 2013, 46,6 ppm). Turkey is ranked as the first on living donation rates.On the other hand, deceased kidney donation ratios are relatively small with respect to European countries $(5 \mathrm{ppm})^{4}$. Turkey is well ahead around the world in living donor ratios. The explanation of this result is: the recipients who cannot find a donor from his close vicinity have to wait for a deceased donor but in general, cannot able to get any

\footnotetext{
${ }^{4}$ Forfurther information please check www.irodat.org registry reports.
} 
kidney. Death donation rate is far below than the average of the world. In this context, studies to increase deceased donation rates should be conducted.

Tracking system that is organized by the Ministry of Health within the entire country is tracking and allocating is done effectively. Even this tracking system, which is attached to a regulation, has some faults; it is serving actively and helpfully ${ }^{5}$. But this system is tracking already registered patients and donors. Possible donors cannot be known. At this point, the main duty is on medical personnel who work at intensive care units and/or emergency units. Employees in charge at these critical units, especially doctors, could be trained to persuade the families to donate the organs of the deceased. Doctors and personnel are usually refraining from asking this type of question. Regular trainings are given to the staff of dialysis and transplantation units by the Ministry of Health periodically. With attempts about this subject, donation rates could be increased. While this kind of demand does not have any illegal aspect; every study will turn as a benefit from many aspects since this kind of attempt would be an encouragement to save lives.

\section{ENCOURAGING BEING A LIVING DONOR}

The effect of monetary incentive on kidney donation rates is analyzed. The quantity of the monetary incentive and the effect of it are investigated. In addition to this, some mechanisms that encourage being a living donor must be settled. There are some reasons to avoid from being a living donor. First of all, being a living donor is scary for most of the people. Living with organ deficiency may cause many problems. However, a missing kidney will not affect the quality of life significantly. Apart from heavyduty employees and sportsmen, living with single kidney does not constitute a problem. "Kidney failure" defines malfunctioning of both kidneys. For this reason, studies for increasing the donation must explicitly explain that there will be no difference about quality of life after the donation.

One of the drawbacks is about religious concerns. Vast majority of the Turkish people have this concern. "Deceased body must have integrity" is the common consensus. Religious Affairs had given fatwa about organ donation, so there is not any inconvenience. This issue should be expressed at every possible platform by the Ministry of Health.

Another concern is about people's lack of trust towards the system. Individuals think that their medical records can be taken by third parties and can be used to find a matching donor and tracked. It should be clarified that these records are confidential and can only be seen by authorized staff.

${ }^{5}$ Daily donor tracking system can be seen at the website: https://organ.saglik. gov.tr/web/ 
Possible donor candidates are afraid of dying during the surgery. In 2014 there is not any recorded death during surgery and only one donor died because of post-surgery complications out of 4263 transplantation. Death risk during this kind of surgery is less than dying because of a car accident. Average death ratio around the world is much more than Turkey's average which is less than $\% 0,1$. For this reason, it should be clearly explained that death risk during the surgery is almost zero.

Broad and comprehensive explanations have to be done while the donor is registered. By clarification of every risks and gains explicitly and completely, there will not be any questions on the head. General knowledge is not clear so there is not any clearance among individuals. Clear information must be given to the registered donors and hesitatations must be eliminated. This informative explanation will create a domino effect and lead the registered donors to persuade non-donors (Thiessenet a.: 2013, Parekh et al.: 2008).

\section{CONCLUSION}

The calculations done in this article are not related with commodification of human body. It is aimed to determine the amount of monetary incentive in order to meet the kidney need that is rising day by day. An approach is done about the quantity of the optimum payment amount. The purpose is not buying a kidney but compensating the loss (this loss should be separated as time, health and quality of life) of consenting donors.

The analysis shows that monetary incentive will get excessive gain for both the individuals and also health and insurance system perspective. The amount of the payment that is calculated in the study is less than yearly dialysis costs. For this reason, applying monetary incentive for kidney donation will be advantageous. Legal regulations, ways of payment, quantity and procedure are subject of separate studies. At the studies conducted about kidney donation, it has been found that people are more eager to donate their kidney instead of selling. On the other hand, different segment of the people consent to donate in return for monetary incentive. By this way, secondary possible donor candidates will be activated and also black market will be blocked.

\section{DISCUSSION}

"Monetary incentive" could be seen as "selling kidney" by large number of people. The distinction must be clearly understood. Furthermore paying incentives for kidney donation is accompanied by moral debates. The focus of discussion is about "commodification of human body".

It is emphasized that if selling kidney will be legalized the 
sellers will usually be poor people and social distinction will deepen. When the individuals become desperate, they try deriving gains and getting out of the problem without considering if it is legal or illegal. Because of that, black market prefers always poor and uncontrolled countries. Yet, it is not compulsory that the donor is poor. When families are reluctant to donate their deceased family member's organ, monetary incentive would be persuasive.

Even a monetary incentive system is applied, it is not sure that all of the kidney demand will be satisfied. Many contestants cannot be "donor" because of their medical incompetence. The main reasons of that are alcohol consumption and genetic disorders.

\section{APPENDIX}

\section{Statistical value of life:}

Statistical value of life is taken from WHO Eurozone data in 2011: 2.487.283 Euro. Since the data and calculations are for the year 2014, it is obligatory to convert it with power purchasing parity. So in 2014;

$1 £=1,2938$ (According to OECD 2009-2014 data)

Over 2014 PPT $1 \$=1,198578 \mathrm{TL}$.

Then; $2.487 .283 \times 1,2938 \times 1,198578=3.857 .080 \mathrm{TL}$.

Minimum value: $1.243 .642 \times 1,2938 \times 1,198578=1.928 .541 \mathrm{TL}$

Maximum value: 3.730 .925 x 1,2938 x 1,198578 $=5.785 .621 \mathrm{TL}$

Death risk of donor during or after the operation related with complication:

$1 / 4263=0,0235 \%$

Monetary equivalence of death risk: $3.857 .080 \times 0,0235 \%=$ $906,4138(1)$

Monetary equivalence of workforce loss:

Minimum civil servant salary $(2014)=2114$ TL.

Healing period is about 4 months, so monetary equivalence of workforce loss:

Monetary equivalence QALY (Quality Adjusted Life Years):

The ratio that was calculated by Becker-Elias: 0,0014985

$3.857 .080 \times 0,0014985=5779,8 \mathrm{TL}$

The total value of monetary incentive: $(1)+(2)+(3)=8638 \mathrm{TL}$

\section{REFERENCES}

Becker, G. S., \& Elias, J. J. (2007). Introducing incentives in the market for liver and cadaveric organ donations. The Journal of Economic Perspectives : A Journal of the American Economic Association, 21(3), 3-24.

Cohen, Lloyd R. 1989. Increasing the Supply of Transplant Organs: The Virtues of a Futures Market. George Washington Law Review, 58:1-51.

Hansmann, Henry. 1989. The Economics and Ethics of Markets for Human Or gans. Journal of Health Politics, Policy and Law 14:57-85. 
Peters, Thomas G. 1991. Life of Death: The Issue of Payment in Cadaveric Organ Donation. Journal of the American Medical Association 265(10):13021305.

DeJong, William, Jessica Drachman, Steven L. Gortmaker, Carol Beasley, and Mi chael J. Evanisko. 1995. Options for Increasing Organ Donation: The Po tential Role of Financial Incentives, Standardized Hospital Pro dures, and Public Education to Promote Family Discussion. Milbank Quarterly 73:463-479.

Jasper, J. D., C. A. E. Nicherson, J. C. Hershey, and D. A. Asch. 1999. The Pub lic's Attitudes toward Incentives for Organ Donation. Transplantation Proceedings31:2181-2184.

Robertson, John A. 1999. The Dead Donor Rule. Hastings Center Report 29(6):6-14. Ubel, Peter A.,Cindy L. Bryce, Laura A. Siminoff, Arthur L. Caplan, and Robert M. Arnold. 2000. Pennsylvania's Voluntary Benefits Program: Evaluat ing an Innovative Proposal for Increasing Organ Donation. Health Af fairs 19(5):206-211.

Sheehy E, Conrad S, Brigham L et al. Estimating the number of potential organ donors in the United States. N EnglJMed 2003; 349: 667-674.

Hariharan S, Johnson C, Bresnahan B, Taranto S, McIntosh M Stablein. Improved graft survival after renal transplantation in the United States, 1988 to 1996. NEJM 2000; 342: 605- 612.

Israni, A. K.,Halpern, S. D., Zink, S., Sidhwani, S. a., \& Caplan, A. (2005). Incent ive models to increase living kidney donation: Encouraging without co ercing. American Journal of Transplantation, 5(1), 15-20.

Mohamed, E.,\&Guella, A. (2013). Public Awareness Survey about Organ Donation and Transplantation. Transplantation Proceedings, 45(10), 34693471.

Mayrhofer-Reinhartshuber, D., Fitzgerald, a, Benetka, G., \& Fitzgerald, R. (2006). Effects of financial incentives on the intention to consent to organ dona tion: a questionnaire survey. Transplantation Proceedings, 38(9), 275660.

Adams F.,Barnett, a H., \& Kaserman, D. L. (1999). Markets for Organs: The Ques tion of Supply. Contemporary Economic Policy, 17(April), 147-155. American Journal of Transplantation, 10(5), 1221-1227.

Ghods, A. J., \& Savaj, S. (2006). Iranian Model of Paid and Regulated Living-Un related Kidney Donation. Clinical Journal of the American Society of Nephrology, 1(6), 1136-1145.

Viscusi, W. K., \& Aldy, J. E. (2003). The Value of a Statistical Life: A Critical Review of Market Estimates throughout the World.

Thiessen, C., Kim, Y. A., Formica, R., Bia, M., \& Kulkarni, S. (2013). Written Informed Consent for Living Kidney Donors: Practices and Compliance with CMS and OPTN Requirements. American Journal of Trans plantation, 13(10), 2713-2721. 
Parekh, A. M., Gordon, E. J., Garg, A. X., Waterman, A. D., Kulkarni, S., \& Parikh, C. R. (2008). Living kidney donor informed consent practices vary between US and non-US centers. Nephrology, Dialysis, Transplantation: Official Publication of the European Dialysis and Trans plant Association - European Renal Association, 23(10), 3316-24.

Stel, V. S., Kramar, R., Leivestad, T., Hoitsma, A. J., Metcalfe, W., Smits, J. M., Jager, K. J. (2012). Time trend in access to the waiting list and renal transplantation: a comparison of four European countries. Nephrology Dialysis Transplantation, 27(9), 3621-3631.

TPH (2016), Kidney Transplant Selection \& Referral Criteria, https://www.tgh. org/kidney-transplant-criteria/, access date: 02.01.2016. 